\title{
Researches regarding scale reduced models for the optimisation of the aerodynamic coefficient
}

\author{
Alexandru Lucian Stanciu ${ }^{1 *}$, Nicoleta Pascu $^{2}$, Constantin Dogariu ${ }^{2}$, and Cristina Mohora ${ }^{2}$ \\ ${ }^{1}$ University Politehnica of Bucharest, Doctoral School of Engineering and Management of \\ Technological Systems, 313 Spl. Independentei, 060042, Bucharest, Romania \\ ${ }^{2}$ University Politehnica of Bucharest, Faculty of Engineering and Management of Technological \\ Systems, Robots and Production Systems Department, 313 Spl. Independentei, 060042, Romania
}

\begin{abstract}
Within the lifecycle of the product, the reduced models are very important for the experimental validation of the prototype. The modelling, simulation and optimization stage precedes the prototype realization, being part of the computer aided design (CAD), computer aided engineering (CAE). The physical model is a physical layout or test setup that reproduces, on a small scale, the features of the original system, in our case the vehicle body layout. The paper presents an automobile reduced model, with the aim to study the aerodynamic theory. The paper presents the algorithms of conceptual design of the scale reduced model, namely: 3D modelling, small scale modelling technology and geometric shape optimization solutions using different CAD-CAE programs.
\end{abstract}

\section{Introduction}

The 21 st century tends to radically change the areas of engineering, terms such as fabrication, digitization, Engineering 4.0 being already well-known. One of the branches where the competition is fierce is the automotive industry. The cost reduction of vehicle components is particularly studied, and scientific research is being done to find the most aerodynamic form of vehicles, characterized by the $\mathrm{C}_{\mathrm{x}}$ aerodynamic resistance coefficient.

This paper presents a methodology for using Computer Fluid Dynamics (CFD) theory coupled with experimental validation by scale reduced models, for improving aerodynamic model. Starting from the first aerodynamic car belonging to the engineer Aurel Persu, the structural examination, (static and dynamic) was well defined and analysed, while the aerodynamic theory is not so easy to apply. Computer fluid dynamic is a well-known method utilised in the study of the automotive aerodynamics. The experimental validation on real models is expensive and difficult to realize, therefore it is proposed a method of validation through reduced models which is easy and cheap to obtain (e.g. by additive technologies). The paper presents the algorithms of conceptual design of the scale reduced model, namely: 3D modelling, small scale modelling technology and geometric shape optimization solutions using different CAD-CAE programs.

\footnotetext{
* Corresponding author: alexandru.stanciu56@gmail.com
} 
The coefficient of aerodynamic strength is denoted by $C_{x}$ and it is mainly determined by the type and the front section of the body that opposes the displacement of the fluid. It is determined experimentally and has the values indicated in figure1.

The minimum strain resistance is obtained in the case of a fusiform object $\left(C_{x}=0.04\right)$, namely the shape of dropping water drop, then semifusiform $\left(C_{x}=0.09\right)$, finding that the shape of the Aurel PERSU body approached the semifusiform form in the vertical plane and tapering horizontally.

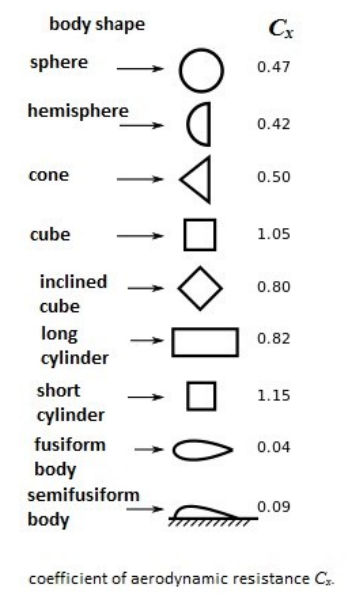

\begin{tabular}{|l|c|c|}
\hline Automobil & Model & $\begin{array}{c}\text { Coeficient } \\
\text { aerodinamic } \\
\text { (Cx) }\end{array}$ \\
\hline Tesla Model S & 2012 & 0.24 \\
\hline Toyota Prius & 2010 & 0.25 \\
\hline Nissan GT-R & 2010 & 0.26 \\
\hline $\begin{array}{l}\text { Opel Insignia } \\
\text { EcoFlex }\end{array}$ & 2008 & 0.26 \\
\hline Mazda 6 & 2009 & 0.27 \\
\hline Nissan Leaf & 2011 & 0.28 \\
\hline Chevrolet Volt & 2010 & 0.28 \\
\hline Peugeot 407 & 2011 & 0.29 \\
\hline Hyundai Sonata & 2006 & 0.3 \\
\hline BMW seria 7 & 2009 & 0.31 \\
\hline WW GTI Mk V & 2006 & 0.32 \\
\hline Ford Fusion & 2010 & 0.33 \\
\hline Aston Martin DB9 & 2004 & 0.34 \\
\hline Mini Cooper & 2008 & 0.35 \\
\hline $\begin{array}{l}\text { Subaru Impreza } \\
\text { WRX }\end{array}$ & 2010 & 0.36 \\
\hline Smart Roadster & 2003 & 0.41 \\
\hline Hummer H2 & 2003 & 0.57 \\
\hline
\end{tabular}

Fig. 1. Coefficient $C_{x}$ according to form and type of automobile [5-6]

Figure 1 shows the values of $C_{x}$ which can increase up to values between $0.24 \sim 0.57$, the body made by Aurel Persu having a $C_{x}=0.22$ according to the literature [4].

\section{The aerodynamic model}

Among the models patented by eng. Aurel PERSU there is also the model shown in figure 2 , which has the lowest coefficient of resistance to advancing. This model was used as basis for the car body modelling presented in this paper.

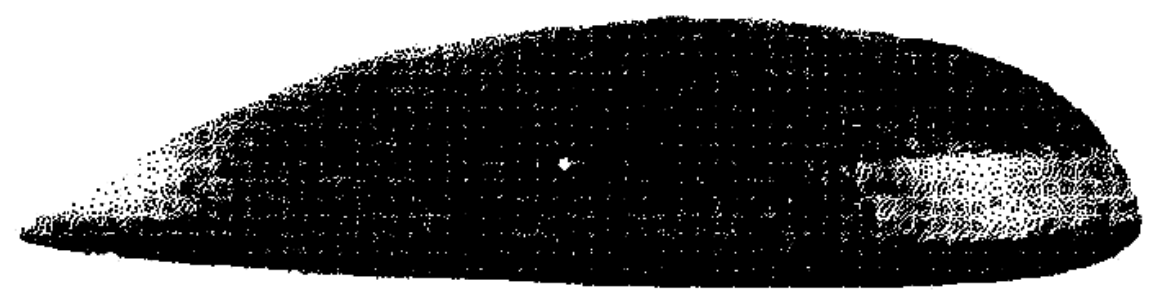

Fig. 2. The aerodynamic model [1]

As initial data, were used the dimensions of the car made by eng. Aurel PERSU, while respecting the legislation that contributes to the traffic safety of the persons and the means involved, according to figure 4 . 

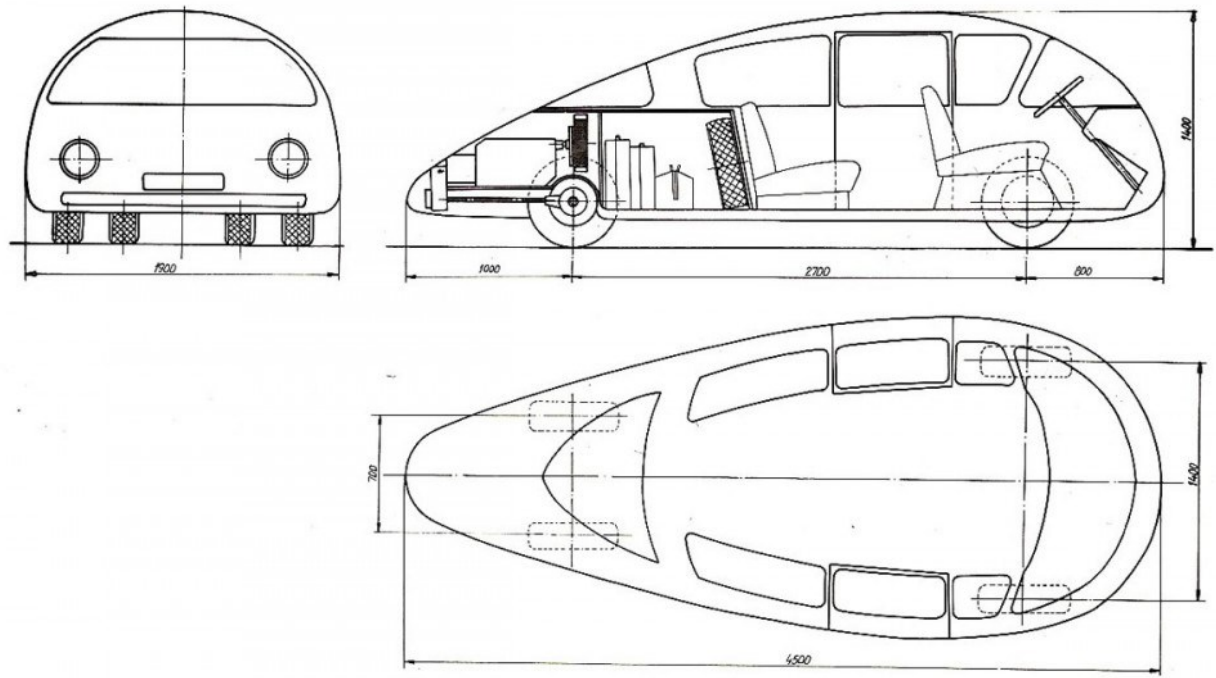

Fig.3. Dimensions of gauge used in modelling [1]

\subsection{The first model version}

Modelling was done using computer-aided design, using AutoCAD, INVENTOR and SolidWorks. The model was made at 1:10 scale. This value was chosen in order to be able to make a small-scale model on a real scale using a 3D printer with acceptable costs.

A network of curves has been made, which has underpinned the generation of body surfaces as shown in figure 4 .

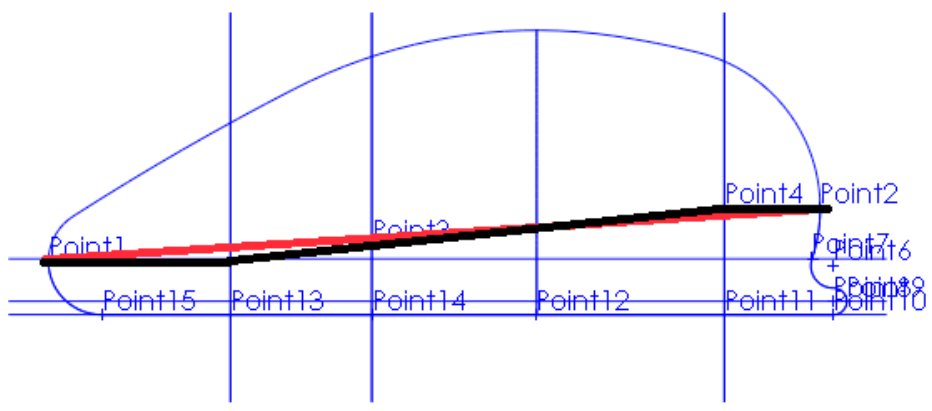

Fig. 4. Generating curve network

In figure 4 there are two distinct areas of demarcation between the top of the body and the lower one as follows:

- The red border, a straight line, used for the first model;

- The black border, a broken line, but which allowed the removal of symmetrical elements, making single left-right elements.

Thus, a first solid was obtained in accordance with figure 5. 


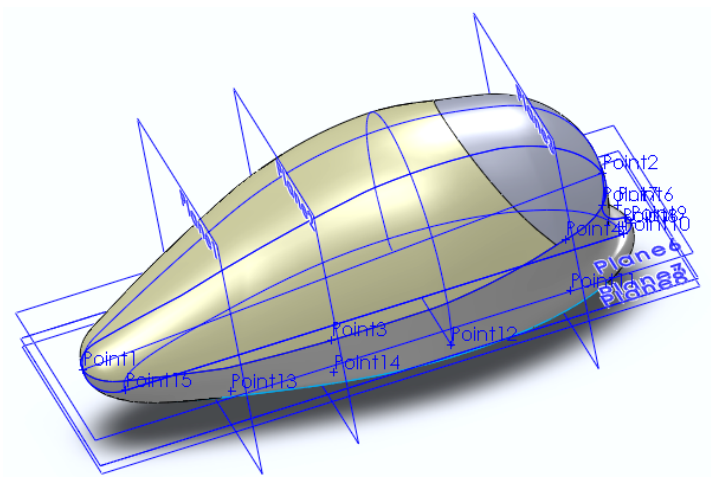

Fig. 5. Model made after surface generation

\subsection{Optimized version}

By analysing the first variant it has been found that by rethinking the boundary between the upper body area and the lower area (fig. 5) some special economic advantages can be obtained by eliminating symmetrical components.

The symmetrical elements that have been reduced to a single element for both the right and the left side are: block of front lights (headlamps), fog lights, rear lights block.

Figure 6 shows the modelling of these elements.

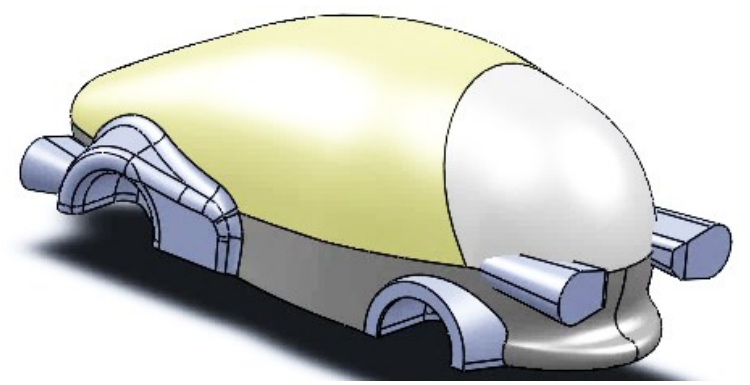

Fig. 6. Modelling the front wing

By operations specific to assisted design (addition, subtraction, intersection of solids), the final model of figure 7 was reached.

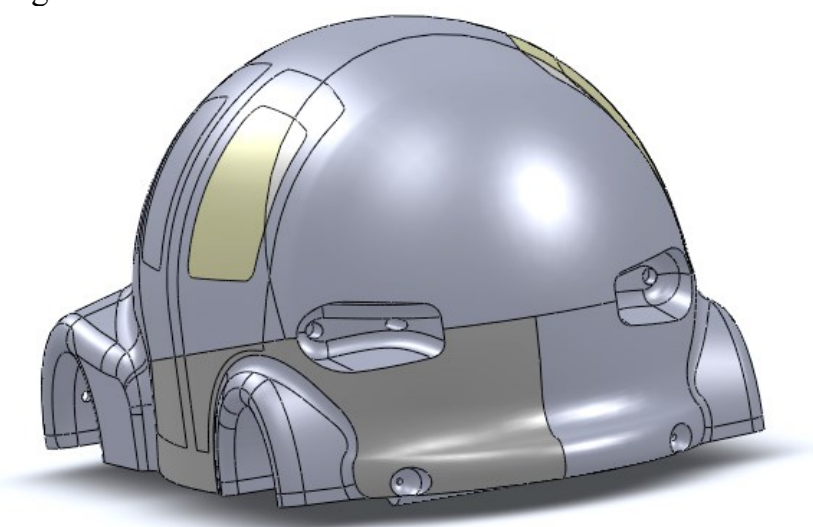

Fig. 7. Final Body Model 
The personal contribution consists of replacing the left-right items with unique elements, where important cost reductions are obtained, as will be presented below.

At the same time there have been marked the positions of the other components that fit the body: the windshield, the side doors, the windows, the trunk door (fig. 8).

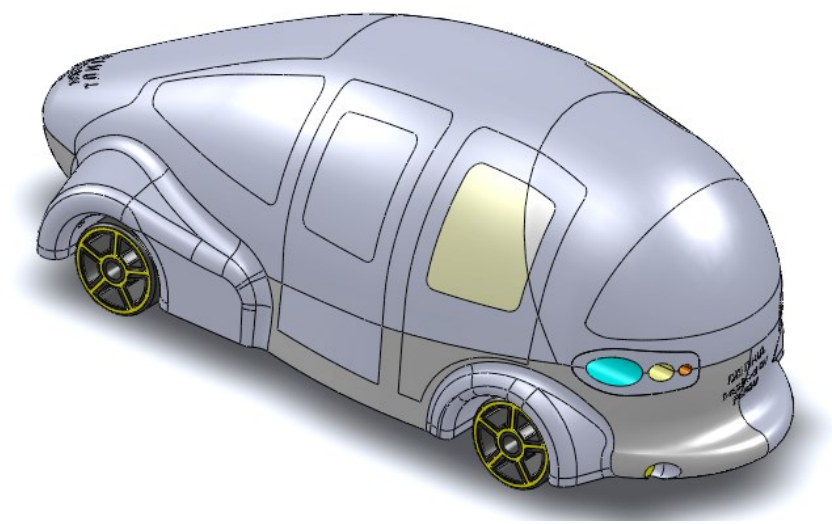

Fig.8. Positioning body elements.

Many products have symmetrical elements in their composition, and cars are no exception to this rule. In many situations the differences between these symmetrical components are very small, but misplacement, leads to a non-commercial aspect or may have negative consequences in operation. This situation has imposed; as early as the time of designing, that these elements to contain physical features to prevent incorrect installation, according to the POKA-YOKE concept [7].

Table 1. Centralized cost analysis

\begin{tabular}{|c|c|c|c|}
\hline \multirow{2}{*}{$\begin{array}{c}\text { Stages of product } \\
\text { - process design } \\
\text { execution }\end{array}$} & $\begin{array}{c}|c| \\
\text { product }- \\
\text { process } \\
\text { LEFT-RIGHT }\end{array}$ & $\begin{array}{c}\text { Identical } \\
(2 \times M I)\end{array}$ & $\begin{array}{c}\text { Identical } \\
\text { (1xMI) }\end{array}$ \\
\hline A & B & C & D \\
\hline 0 & 0 & 0 & 5 \\
\hline 1 & 5 & 5 & 13 \\
\hline 2 & 10 & 13 & 20 \\
\hline 3 & 18 & 20 & 45 \\
\hline 4 & 26 & 70 & 48 \\
\hline 5 & 33 & 73 & 50 \\
\hline 6 & 38 & 75 & 51 \\
\hline 7 & 63 & 76 & \\
\hline 8 & 88 & & \\
\hline 9 & 91 & & \\
\hline 10 & 94 & & \\
\hline 11 & 96 & & \\
\hline 12 & 98 & & \\
\hline 13 & 100 & & \\
\hline
\end{tabular}

Figure 9 shows the number of distinct steps required for product-process design (column A), where the current situation (100\% cumulative costs, column B) was considered as reference and 2 solutions for the results obtained by the current research (column $\mathrm{C}$ and column D). The data in column D presents maximum economic advantages and is a real 
situation, because at the stage of launching a new product, the production volume will increase in stages, reaching a maximum after a period of time, so there is no need for a maximum production capacity, from the first stage of launching the product on the market.

The graph in figure 9 was made, illustrating the economic advantage of unifying the LEFT-RIGHT type elements.

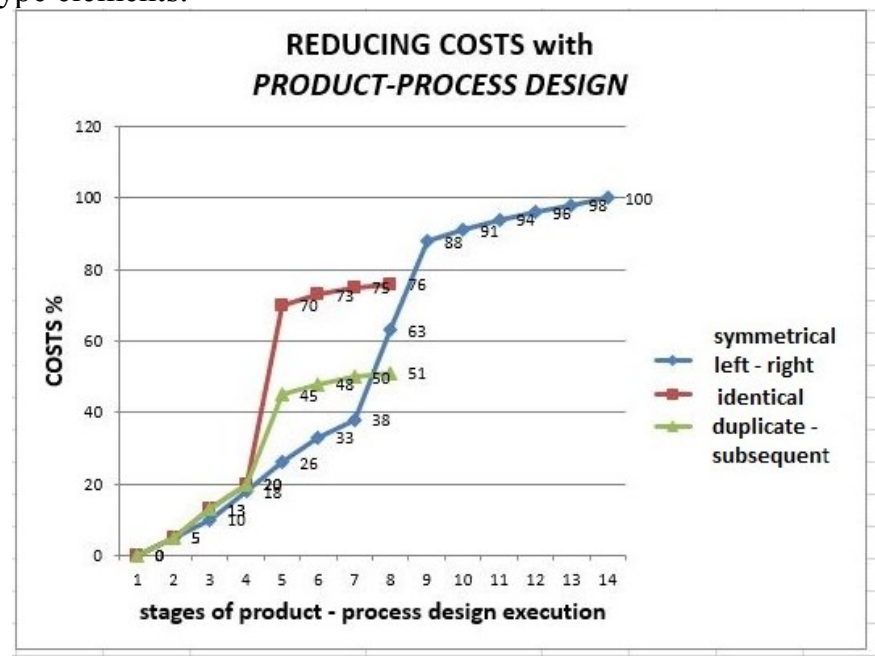

Fig. 9. Cost reduction by designing unique elements

\section{Experimental procedures through the physical model on a small scale}

The completion of the bodywork elements as well as the other bodywork elements allowed the move to achieving the real scale model.

With respect to the main stages presented above, the actual physical model shown in figure 10 was realized.

Due to the gauge boundaries that could be executed on the 3D printer, the body was split in 2 parts, which were later assembled.

The similitude theory applied for aerodynamical analysis on the reduced scale models will be utilized to determine the speed of the wind tunnel. The main assumptions:

- Compressibility of the air is ignored.

- The wind tunnel walls are far enough away to not interfere with the aerodynamic drag on the car model.

- The model is geometrically similar to the prototype.

- Both the air in the wind tunnel and the air flowing over the prototype car are at standard atmospheric pressure.

- The air properties used in the simulation: $T=25^{\circ} \mathrm{C}$ and atmospheric pressure, density is $\rho=1.184 \mathrm{~kg} / \mathrm{m}^{3}$ and the dynamic viscosity is $\mu=1.84910^{-5} \mathrm{~kg} / \mathrm{m} \cdot \mathrm{s}$.

- The prototype dimensions are $L_{P}$ and the model dimensions are $L_{M}$.

Since there is only one independent the similarity is achieved if Reynolds number for the prototype is identical with the Reynold number of the reduced model:

$$
\text { - } \operatorname{Re}_{P}=\frac{\rho_{P} \cdot v_{P} \cdot L_{P}}{\mu_{P}}=\operatorname{Re}_{M}=\frac{\rho_{M} \cdot v_{M} \cdot L_{M}}{\mu_{M}}
$$




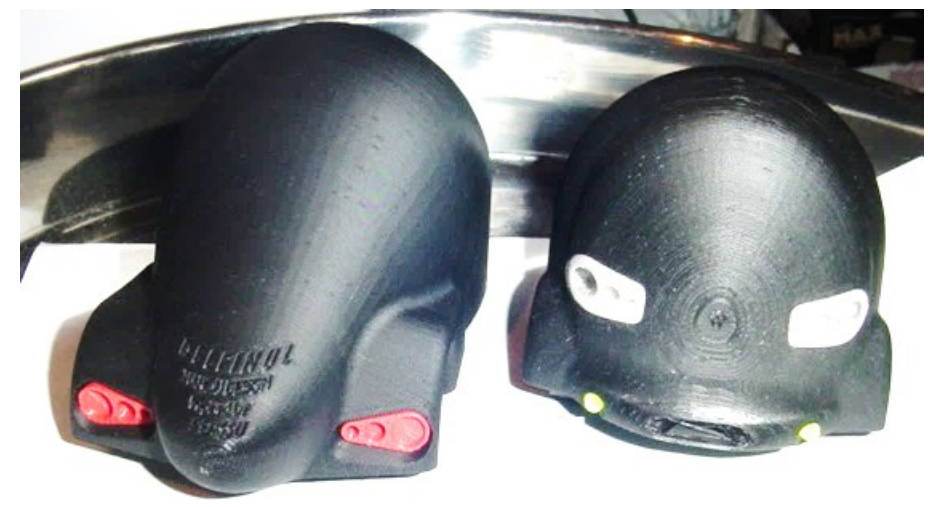

Fig. 10. Actual body with 2 non-assembled parts

The wind speed for the model is:

$$
v_{M}=v_{P} \cdot \frac{\rho_{P} \cdot \mu_{M}}{\rho_{M} \cdot \mu_{P}} \cdot \frac{L_{P}}{L_{M}}
$$

Because, starting from the assumption

$$
\frac{\rho_{P} \cdot \mu_{M}}{\rho_{M} \cdot \mu_{P}}=1
$$

Results that the windspeed for the model is in the ratio of $\frac{L_{P}}{L_{M}}$.

In conclusion, the model scale should be reduced in such way to not increase very much the windspeed in the experimental model. Using reduced model, it is recommended to replace the air with other fluid, for a better representation of the obtained results.

The result is that pressure distribution: the maximum pressure is about 1.15 bar, but the distribution area is very small, positioned in the front of the model.
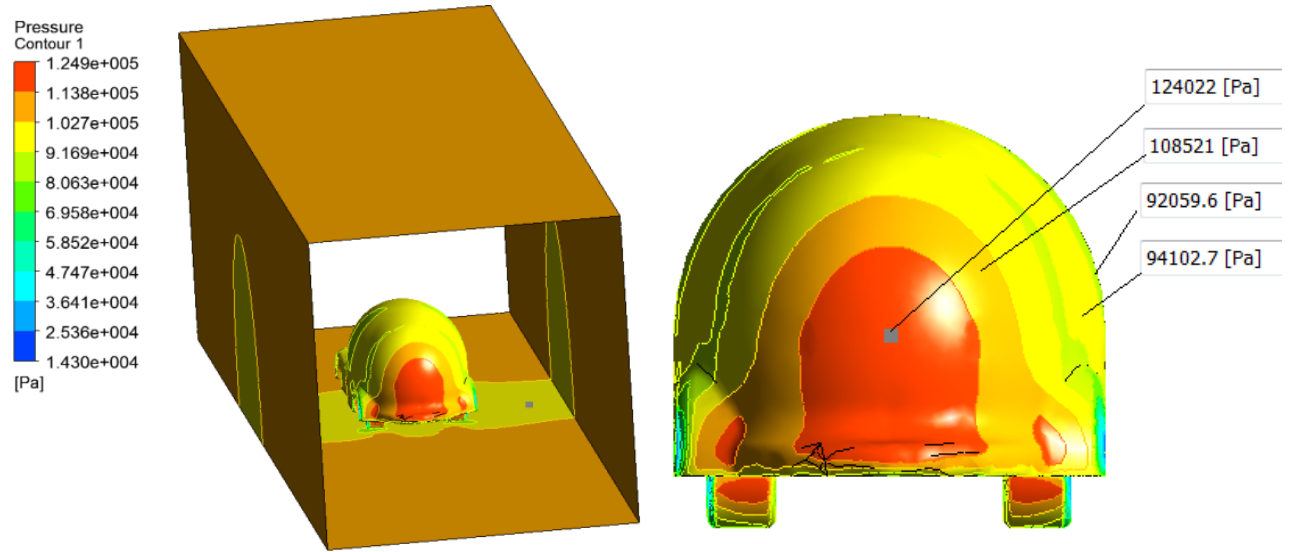

Fig.11. Pressure distribution for the reduced model in wind tunnel (front view)

On the back side of the model the pressure is not very low, the average value is about 0.98 bar. The air flow speed distribution: some regions are characterized by very high speed ( $>300 \mathrm{~m} / \mathrm{s}$ around the wheels regions). 
It is visible that the maximum pressure is distributed on a very small area. Also, the difference between pressure on the front side of the car and from the rear side of the car is very small, as result of a very good aerodynamic of the model.

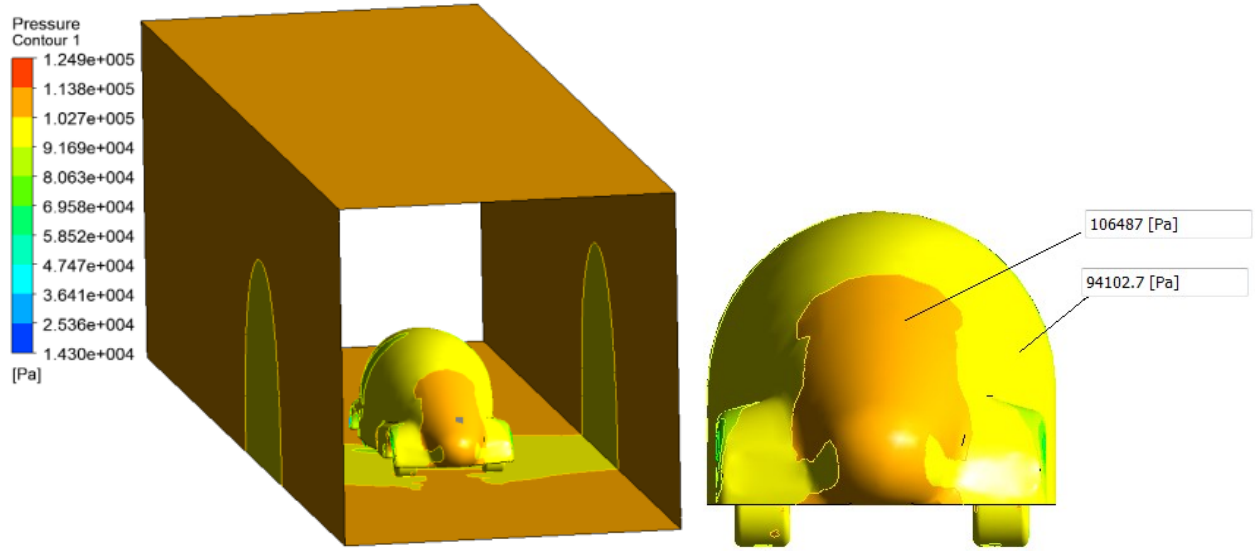

Fig.12. Pressure distribution for the reduced model in wind tunnel (rear view)

The air flow analysis is presented in the below pictures. Using the similitude theory, the wind speed at the entrance of the wind tunnel is very high. This represents a negative aspect when the scale reduced models are used.

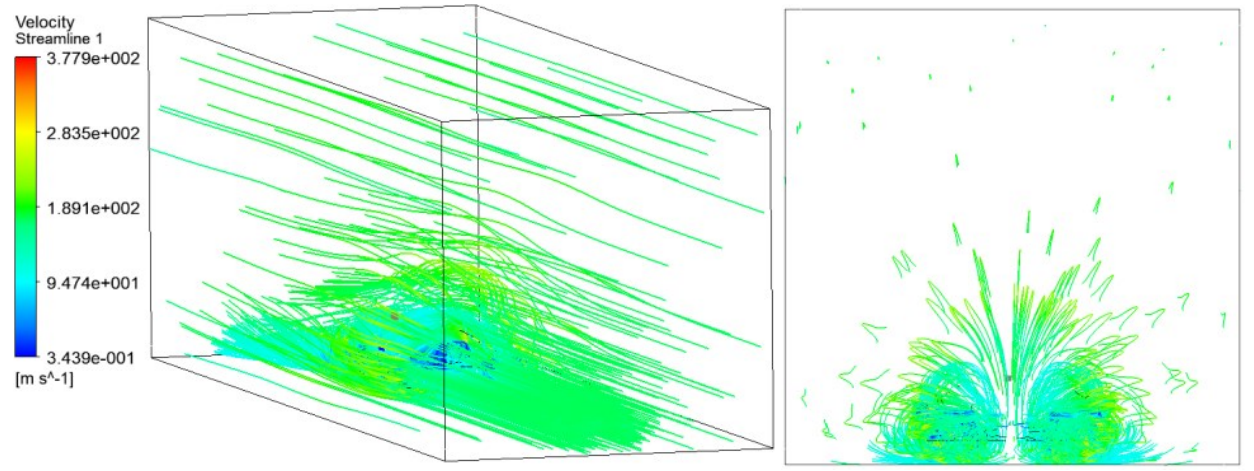

Fig.13. Air speed distribution (front view)

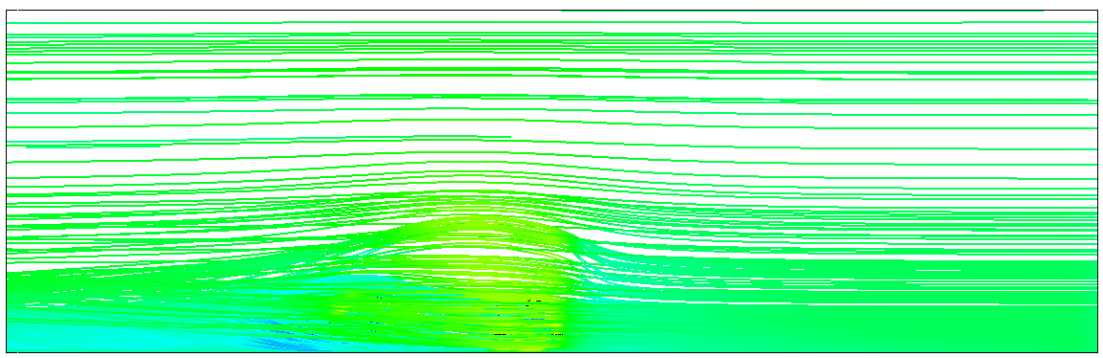

Fig.14. Air speed distribution (lateral view)

The air speed around some regions closed to the car wheels is very high. The optimisation of the car body in these regions is limited. But, generally, the airflow around the car body is continuous and the turbulences are very low. 
Analysing the results, the conclusion is that, around the automobile, the air speed and the air resistance is very small.

The validation of these results will be presented in a future paper.

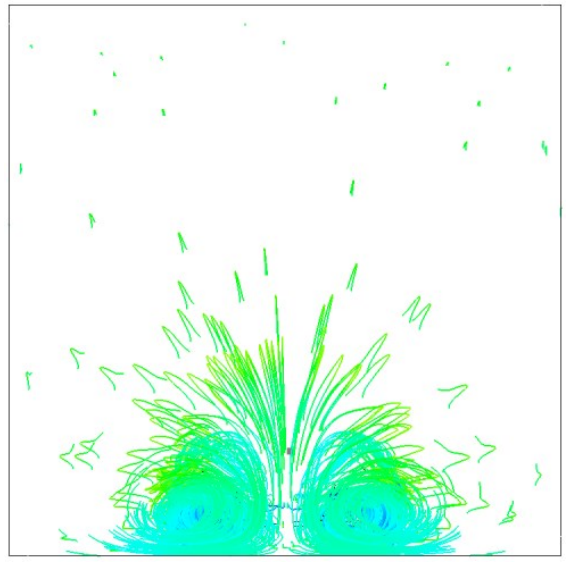

Fig.15. Air speed distribution (rear view)

\section{Conclusions}

Computer-aided design, access to $3 \mathrm{D}$ printers generate real scale models. The scale at which these patterns are made is correlated with the possibilities of the $3 \mathrm{D}$ printer. The actual patterns obtained can be used for various practical simulations, confirming or suggesting changes to the computer-assisted design models, which in turn have undergone theoretical simulations. The aerodynamic resistance represents, in addition to the rolling resistance, the essential factor driving the dynamics of a vehicle and the ratio between cost and efficiency. When the aerodynamic resistance is higher, the force required in order to accelerate the vehicle at a certain speed and to maintain that running speed should be higher.

Aerodynamic strength occurs because of the removal of the air around the vehicle and its rubbing against the surface of the vehicle. It acts in the direction opposite to the movement of a vehicle and depends on the following factors: the speed of the vehicle, the front surface of the vehicle, the aerodynamics resistance coefficient $\left(\mathrm{c}_{\mathrm{w}}\right)$ and air density.

After the tests carried out, we can conclude that the proposed model satisfies very well the conditions of a superior aerodynamics in the area of the model, the density of the air is very low (the areas coloured with blue).

\section{References}

1. M.D., Cazacu s.a., Aurel Persu, inventator al automobilului aerodinamic, 88 (2013)

2. M.D., Iozsa, Caroserii pentru autovehicule rutiere, 123 (2016)

3. A.Yunus Çengel, John M. Cimbala, Solutions Manual for Fluid Mechanics: Fundamentals and Applications, 3, (2013)

4. B. Kittirungsi, Quantification of Approximate Similitude and use in Multiobjective Design, $\mathrm{Ph}$.D.Thesis, University of Michigan, (2008)

5. http://www.e-automobile.ro/categorie-dinamica/79-coeficient-aerodinamic-cx.html.

6. http://eceregulation.blogspot.ro/2014/07/ece-r12701-upgrade.html 